\title{
An Undergraduate Experiment Using Microwave-Assisted Synthesis of Metalloporphyrins: Characterization and Spectroscopic Investigations
}

\author{
Shaikha S. Al Neyadi, Ahmed Alzamly, Abdullah Al-Hemyari, Ibrahim M. Tahir, \\ Saeed Al-Meqbali, M. A. Ali Ahmad, Muna Bufaroosha* \\ Department of Chemistry, College of Science, UAE University, Al-Ain, UAE \\ *Corresponding author: muna.bufaroosha@uaeu.ac.ae
}

Received November 22, 2018; Revised January 05, 2019; Accepted February 04, 2019

\begin{abstract}
The effectiveness of microwave-assisted synthesis of 5,10,15,20-tetraphenylporphyrin and its corresponding to metal complexes of (Bi (III), Zn (II) and Ni (II)) are described. Moreover, the synthesized metalloporphyrins that were obtained with reasonable yields were characterized using UV-vis, ${ }^{1} \mathrm{H}-\mathrm{NMR}$ and IR.
\end{abstract}

Keywords: porphyrins, metalloporphyrins, microwave synthesis

Cite This Article: Shaikha S. Al Neyadi, Ahmed Alzamly, Abdullah Al-Hemyari, Ibrahim M. Tahir, Saeed Al-Meqbali, M. A. Ali Ahmad, and Muna Bufaroosha, "An Undergraduate Experiment Using Microwave-Assisted Synthesis of Metalloporphyrins: Characterization and Spectroscopic Investigations." World Journal of Chemical Education, vol. 7, no. 1 (2019): 26-32. doi: 10.12691/wjce-7-1-4.

\section{Introduction}

Porphyrins and metalloporphyrins are synthetically important compounds due to their aromatic character, inner chelating pockets, and varying peripheral carbon chains. These have endorsed scientists to discover new and unique chemical reactions. Porphyrin macrocycles play an important role in areas such as photodynamic therapy of cancer (PDT), photoinactivation of microorganisms (aPDT), catalysis, electronics, solar cells production, and others. [1] The metalloporphyrin rings play an important role in important biological systems. The use of these tetrapyrrolic macrocycles is strongly dependent on their structures and that's why it is so important to develop or to improve synthetic strategies to reach novel derivatives by derivatization of the porphyrin macrocycle. [2] Traditionally, porphyrins and metalloporphyrins syntheses have been carried out in acidic conditions such as propanoic acid or in a halogenated solvent. [3] The use of acid catalysis is an important and efficient requirement for the synthesis of meso-substituted porphyrins. The acid catalyst is responsible for the protonation of the carbonyl group of the aldehydes, which are then attacked by pyrrole in an aromatic electrophilic substitution, leading to the formation of the tetrapyrrolic chain. In most cases, oxidizing reagents are used to convert the initial porphyrinogen product to porphyrin. The porphyrin nucleus is a tetradentate ligand in with the space available for a coordinated metal has maximum diameter of approximately $3.7 \AA$. The porphyrin ring system and the porphyrin complexes with transition metal ions are very stable. [4] Microwave-assisted organic synthesis, nowadays, has been thoroughly explored and developed. The use of microwaves affords a set of reaction conditions unachievable by conventional heating and has already undeniably demonstrated its generally successful technology in the organic chemistry field, allowing significant improvements in several types of synthetic reactions. [5] Generally, this technique leads to a remarkable decrease in reaction times, an increase of yields and, frequently, an extraordinary enhancement in selectivity, which also permit a substantial reduction in the solvents employed and allows a broad series of reactions to be carried out in the solid phase [6], the latter being an extremely desirable goal from both the environmental and economical evaluations. Bearing in mind the valuable application of porphyrins and metalloporphyrins, we present herein a fast and convenient procedure for the synthesis of tetraphenylporphyrin and metalloporphyrins under microwave irradiation. Moreover, it has been characterized with UV-visible spectra, H-NMR spectra and infrared spectra.

\section{Materials and Methods}

\subsection{General}

All reagents and chemicals were purchased from Sigma-Aldrich and used without further purification. Benzaldehyde $\left(\mathrm{C}_{7} \mathrm{H}_{6} \mathrm{O}\right)$, pyrrole $\left(\mathrm{C}_{4} \mathrm{H}_{5} \mathrm{~N}\right)$, acetic acid $\left(\mathrm{CH}_{3} \mathrm{COOH}\right)$, Zinc acetate dehydrate $\left(\mathrm{Zn}\left(\mathrm{CH}_{3} \mathrm{CO}_{2}\right)_{2} \cdot 2 \mathrm{H}_{2} \mathrm{O}\right)$, Nickel(II) acetate tetrahydrate $\left(\mathrm{Ni}\left(\mathrm{CH}_{3} \mathrm{CO}_{2}\right)_{2} \cdot 4 \mathrm{H}_{2} \mathrm{O}\right.$, $)$ Bismuth(III) nitrate pentahydrate $\left(\mathrm{Bi}\left(\mathrm{NO}_{3}\right)_{3} \cdot 5 \mathrm{H}_{2} \mathrm{O}\right)$ and 
chloroform- $d\left(\mathrm{CDCl}_{3}\right)$ were purchased from Sigma-Aldrich Chemical Company (Sigma Chemical Co., St. Louis, MO, USA). Thin-layer chromatography (TLC) was performed on silica gel glass plates (Silica gel, $60 \mathrm{~F}_{254}$, Fluka) and spots were visualized under UV lamp. Column chromatography was performed on Kieselgel S (Silica gel S, 0.063-0.1mm). Melting points recorded on a Gallenkamp apparatus and are uncorrected. Infrared spectra were measured using $\mathrm{KBr}$ pellets on a Thermo Nicolet model 470 FT-IR spectrophotometer. ${ }^{1} \mathrm{H}-\mathrm{NMR}$ spectra were recorded on Varian, $400 \mathrm{MHz}$ instruments by using DMSO- $d_{6}$ and $\mathrm{CDCl}_{3}$ solutions and tetramethylsilane (TMS) as an internal reference. Microwave-assisted reactions performed using a microwave reactor (Discover-CEM Corporation). The reactor uses a continuous, focused microwave power-delivery system with an operator-selectable power output of up to $300 \mathrm{~W}$. Reactions performed in glass vials $(10 \mathrm{ml})$ sealed with a septum. The temperature of the reaction mixture controlled using a calibrated infrared temperature controller mounted under the reaction vessel. Absorption measurements were carried out using Agilent 8453 spectrophotometer supported with $1.0 \mathrm{~cm}$ quartz cells (Austria).

\subsection{Synthesis of Porphyrin 3 and Metalloporphyrin 3a-c}

\subsubsection{Synthesis of Meso-tetraphenylporphyrin (TPP) 3}

Benzaldehyde $(10 \mathrm{mmol})$ and pyrrole $(10 \mathrm{mmol})$ were added to amixture of propionic acid $(3.5 \mathrm{~mL})$ and nitrobenzene $(1.5 \mathrm{~mL})$ in $35 \mathrm{ml}$ CEM Microwave vial. The reaction mixture heated under microwave irradiation $\left(100^{\circ} \mathrm{C}\right)$ for $5-10 \mathrm{~min}$. The progress of the reaction was monitored by TLC and after completion porphyrin was crystallized overnight from the concentrated crude product mixture by addition of methanol. The dark purple solid was then filtered off, washed with methanol, dried and re-crystallized in methylene chloride/methanol to give the porphyrin in a good yield; dark purple solid; yield 57.4\%; mp 300 ${ }^{\circ}$; IR $\left(\mathrm{KBr}, \mathrm{cm}^{-1}\right)$ : $3314(\mathrm{NH}), 3052$ and 2923 (ArH), 1472 and 1440 (NH bending), 698 (out of plane bending deformation, monosubstituted benzene), 1593 $(\mathrm{C}=\mathrm{C}), 1490(\mathrm{C}=\mathrm{N}) ;{ }^{1} \mathrm{H}-\mathrm{NMR}\left(400 \mathrm{MHz}, \mathrm{CDCl}_{3}\right) \delta$ ppm: 1.54 (brs, 2H, -NH), 7.76 (m, 12H, aromatic), 8.23 (dd, $8 \mathrm{H}$, aromatic, $J=8.0 \mathrm{~Hz}$ ), 8.87 (s, 8H, $\mathrm{H}_{\beta}$-pyrrolic); ${ }^{13} \mathrm{C}-\mathrm{NMR}\left(100 \mathrm{MHz}, \mathrm{CDCl}_{3}\right) \quad \delta$ ppm: 120.1, 126.7, 127.7,128.8, 129.1, 134.6, 142.2.

\subsubsection{Synthesis of Metalloporphyrin 3a-c}

The meso-tetraphenylporphyrin (1 mmol) and the appropriate metal salts $(5 \mathrm{mmol})$ were added to $N, N$-dimethylformamide $(5 \mathrm{~mL})$ in $35 \mathrm{ml}$ CEM Microwave vial. The reaction mixture heated under microwave irradiation $\left(100^{\circ} \mathrm{C}\right)$ for $5-10 \mathrm{~min}$. The reaction was monitored over time by UV-vis absorption spectrophotometry until the typical degeneracy of the $\mathrm{Q}$ bands was observed. After cooling to room temperature, the crude product mixture was washed with ice-cold distilled water $(50 \mathrm{~mL})$ and the resulting suspension was refrigerated for a few hours. Filtration of the precipitate under reduced pressure followed by washing with distilled water $(50 \mathrm{~mL})$ and drying, firstly overnight in an oven at $120^{\circ} \mathrm{C}$ and then in vacuo at room temperature, yielded the metallo-porphyrins as crystalline solids 3a-c.

Bismuth(III) 5,10,15,20-tetraphenylporphyrin (BiTPP) (3a): dark green solid; yield 51\%; $\mathrm{mp}>400^{\circ} \mathrm{C}$; IR $(\mathrm{KBr}$, $\mathrm{cm}^{-1}$ ):1559, 1533, 1440, 1384, 1002, 795, 721; ${ }^{1} \mathrm{H}-\mathrm{NMR}$ (400 $\left.\mathrm{MHz}, \mathrm{CDCl}_{3}\right) \delta$ ppm: 7.79 (m, 12H, aromatic), 8.34 (dd, 8H, aromatic, J = 8.0 Hz), 9.21 (s, 8H, $\mathrm{H}_{\beta}$-pyrrolic).

Nickel(II) 5,10,15,20-tetraphenylporphyrin (NiTPP) (3b): dark purple solid; yield 94\%; $\mathrm{mp}>400^{\circ} \mathrm{C}$; IR $\left(\mathrm{KBr}, \mathrm{cm}^{-1}\right)$ : 1598, 1462, 1440, 1384, 1006, 793, 695; ${ }^{1} \mathrm{H}-\mathrm{NMR}$ (400 $\left.\mathrm{MHz}, \mathrm{CDCl}_{3}\right) \delta$ ppm: 7.69 (m, 12H, aromatic), 8.00 (dd, $8 \mathrm{H}$, aromatic, $\mathrm{J}=8.0 \mathrm{~Hz}$ ), 8.74 (s, 8H, $\mathrm{H}_{\beta}$-pyrrolic).

Zinc(II) 5,10,15,20-tetraphenylporphyrin (ZnTPP) (3c): Red-purple solid; yield 96\%; mp $>400^{\circ} \mathrm{C}$; IR $\left(\mathrm{KBr}, \mathrm{cm}^{-1}\right)$ : 1596, 1482, 1439, 1339, 1002, 797, 752; ${ }^{1} \mathrm{H}-\mathrm{NMR}(400$ $\left.\mathrm{MHz}, \mathrm{CDCl}_{3}\right) \delta$ ppm: 7.77 (m, 12H, aromatic), 8.24 (dd, $8 \mathrm{H}$, aromatic, $\mathrm{J}=8.0 \mathrm{~Hz}$ ), 8.96 (s, 8H, $\mathrm{H}_{\beta}$-pyrrolic).

\subsection{UV-Visible Studies}

A UV-Visible spectrophotometer with $1 \mathrm{~cm}$ quartz cells was used for all the spectroscopic studies. All measurements were recorded in the wavelength range 200-500 nm at room temperature. Stock solutions of meso-tetraphenylporphyrin $\mathbf{3}$ and Metalloporphyrins 3a-c were prepared by dissolving appropriate amounts of each compound in dichloromethane to final concentrations of $10^{-6} \mathrm{M}$.

\section{Results and Discussion}

\subsection{Synthesis}

Microwave-assisted processes have been recently used as a fast and clean tools for organic synthesis. [7] In the synthesis of the porphyrin we decided to use the method of Gonsalves et al [8], which employs propionic acid and nitrobenzene as an oxidant, Gonsalves method leads to the precipitation of the porphyrin from the reaction medium and the total absence of chlorins in the final products thus facilitating its isolation and purification. At higher temperatures nitrobenzene is not only a good inductor of crystallization of the porphyrins but also a good oxidant of the intermediates, porphyrinogen and/or chlorin to the corresponding porphyrins. The reaction was carried out through an electrophilic aromatic substitution reaction by the combination of equimolar amounts of benzaldehydes and pyrrole using a very low quantity of propionic acid followed by microwave irradiation in a very short time period (5-10 min.) gave reasonable yields of meso-tetraphenylporphyrin (Table 1). The preparation of a porphyrin complex is a two-step process, which includes synthesis of a ligand and reaction of a ligand with appropriate metal salts (Scheme 1). In this paper, the metallation of porphyrin was carried out by two steps: (1) the preparation of tetraphenylporphyrin (TPP) followed by metallation with the corresponding metal ion. The metalloporphyrins 3a-c have been produced in in relatively good yield (51-96\%) (Table 1). Structures of the synthesized tetraphenylporphyrin $\mathbf{3}$ and its complexes 3a-c were confirmed on the bases of ${ }^{1} \mathrm{H}$ NMR, IR and UV/Vis spectroscopy. 


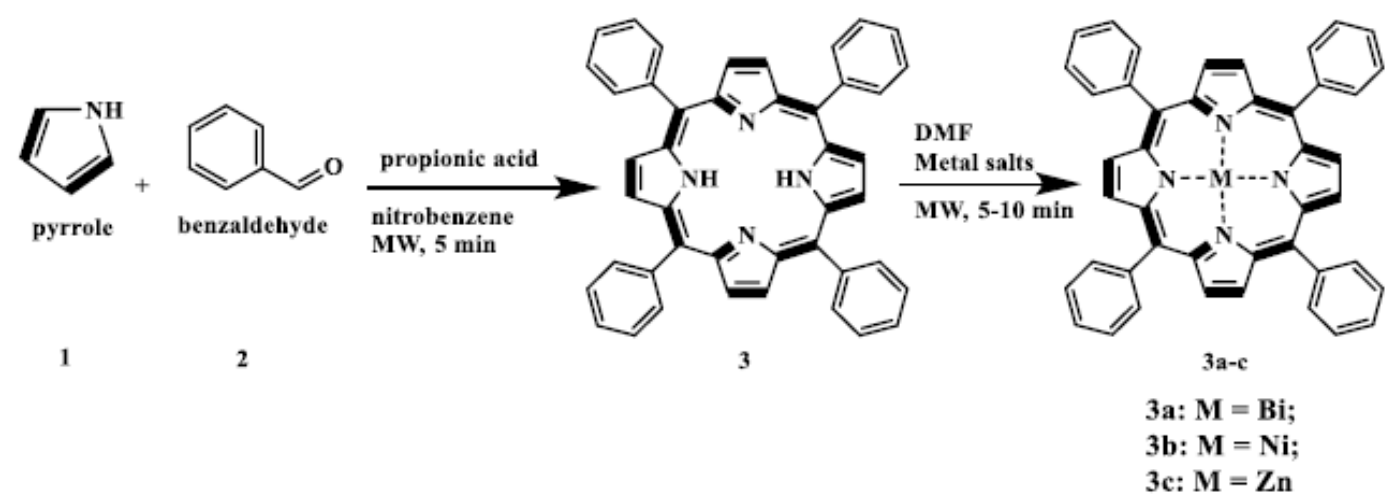

Scheme 1. Microwave-assisted synthesis of 5, 10, 15, 20-tetraphenylmetalloporphyrins

Table 1. Yields, Reactions Time And $\mathbf{R}_{f}$ Values Using The Microwave Synthesis Of $\mathrm{H}_{2}$ TPP And MTPP (M= Ni, Zn And Bi Ions)

\begin{tabular}{|c|c|c|c|c|}
\hline Comp. & Porphyrin & $\mathrm{R}_{\mathrm{f}}$ & Time (min) & \% Yield \\
\hline 3 & $\mathrm{H}_{2}$ TPP & 0.40 & 5 & 57.4 \\
\hline 3a & BiTPP & 0.34 & 10 & 51 \\
\hline 3b & NiTPP & 0.56 & 7 & 94 \\
\hline 3c & ZnTPP & 0.32 & 7 & 96 \\
\hline
\end{tabular}

\subsection{Spectroscopic Analysis}

\subsection{1. ${ }^{1} \mathrm{H}$ NMR Study}

${ }^{1} \mathrm{H}$ NMR spectral studies have been carried out to verify the formation of porphyrin and its metal derivatives. ${ }^{1} \mathrm{H}$ NMR spectra of product were measured in deuterated chloroform, $\mathrm{CDCl}_{3}$, as a solvent at $400 \mathrm{MHz}$ at $298 \mathrm{~K}$. Table 2 summarizes the characteristic ${ }^{1} \mathrm{HNMR}$ Shifts for
$\mathrm{H}_{2} \mathrm{PPT}$ and MTTP. The spectrum for the free porphyrin (Figure 1) show a singlet band for inner imino protons of the H2TPP. The singlet NH peak (due to rapid exchange of - $\mathrm{NH}$ protons) is found to be very high field (1.54 ppm), since they are located within the shielded core of the porphyrin ring. A multiple signal resonates at $\delta=7.74$ ppm and integrated into 12 protons is assigned to aromatic protons. Two doublets of doublet appeared at $\delta=8.22$ ppm and $\delta=8.24 \mathrm{ppm}$ corresponding to aromatic protons $(J=4.0 \mathrm{~Hz})$ and integrated into 8 protons; while a broad singlet band resonate at $\delta=8.87 \mathrm{ppm}$ due to $\beta$ - protons of pyrrole ring and integrated into 8 protons (Figure 1, Table 2). The ${ }^{1} \mathrm{H}-\mathrm{NMR}$ data of free base porphyrins and in comparison with metalloporphyrins showed the disappearance of the $\mathrm{NH}$ peak at around $1.54 \mathrm{ppm}$ indicates the formation of metalloporphyrin. This is the distinguishing factor between porphyrins and metalloporphyrins.

Table 2. ${ }^{1} \mathrm{HNMR}$ Chemical Shifts (in $\delta$ ppm) For $\mathrm{H}_{2} \mathrm{PPT}$ And The Metalized Porphyrin $\left(\mathrm{CDCl}_{3}\right)$

\begin{tabular}{|c|c|c|c|c|c|}
\hline Porphyrin & $\beta$-Pyrrole & $o$-phenyl & $m$-phenyl & $p$-phenyl & N-H \\
\hline H2PPT & $8.87,(\mathrm{~s})$ & $8.23,(d d)$ & $7.76,(m)$ & $7.76,(m)$ & $1.54,(\mathrm{brs})$ \\
\hline ZnPPT & 8.96 & 8.24 & 7.77 & 7.77 & - \\
\hline NiPPT & 8.74 & 8.00 & 7.69 & 7.69 & - \\
\hline BiPPT & 9.21 & 8.34 & 7.79 & 7.79 & - \\
\hline
\end{tabular}

$\mathrm{s}=$ singlet, $\mathrm{dd}=$ doublet of doublet , $\mathrm{m}=$ multiplet

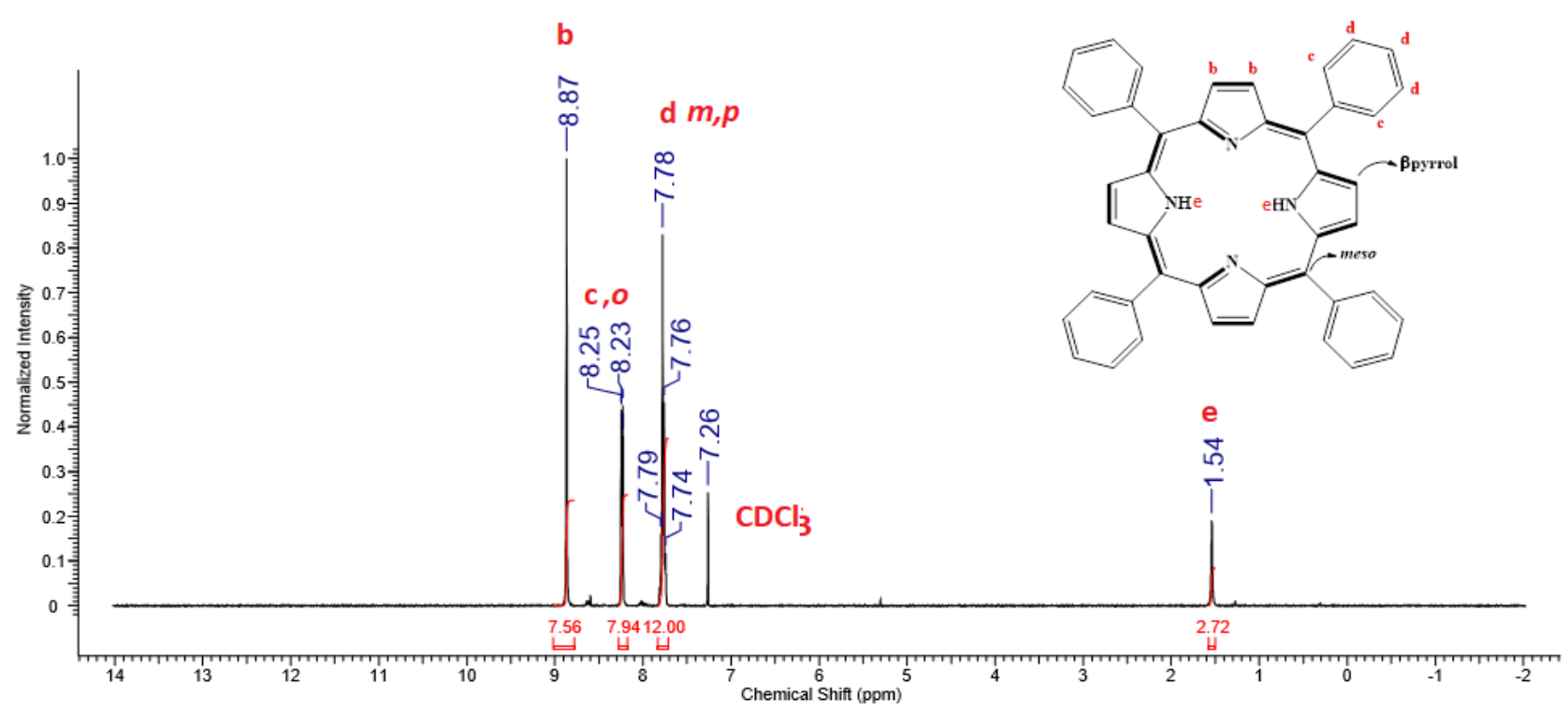

Figure 1. ${ }^{1} \mathrm{H}$ NMR spectra of free $\mathrm{H}_{2} \mathrm{TPP}$ in $\mathrm{CDCl}_{3}$ at $298 \mathrm{~K}$ 

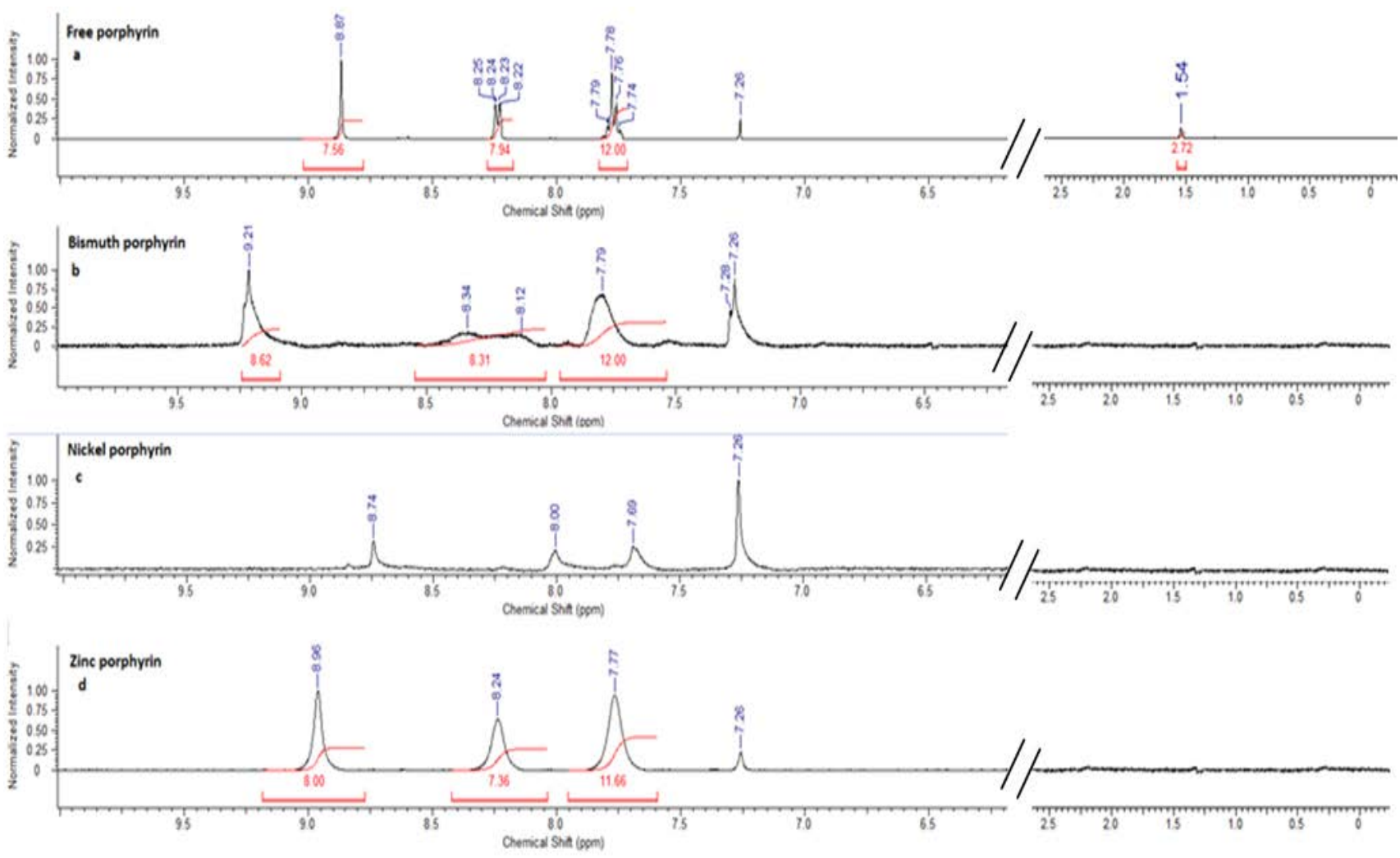

Figure 2. ${ }^{1} \mathrm{H}$ NMR spectra of (a) free $\mathrm{H}_{2} \mathrm{TPP}$, (b) bismuth (III) complexe of $\mathrm{H}_{2} \mathrm{TPP}$ (3a), (c) Nickel (II) complexe of $\mathrm{H}_{2} \mathrm{TPP}$ (3b), (d) zinc (II) complexe of $\mathrm{H}_{2} \mathrm{TPP}$ (3c) in $\mathrm{CDCl}_{3}$ at $298 \mathrm{~K}$

In the Figure $2 \mathrm{~b},{ }^{1} \mathrm{H}$ NMR spectrum of the meso-tetraphenylporphyrin and its $\mathrm{Bi}$ derivative showes that the $\beta$-pyrrole protons resonate as a singlet at $9.21 \mathrm{ppm}$ and the meso-aryl ortho protons resonate as doublet at $8.34 \mathrm{ppm}$ and $7.79 \mathrm{ppm}$ for meso-aryl meta and para protons, respectively, which are slightly downfield (deshielded) compared to free porphyrin.

${ }^{1} \mathrm{H}$ NMR spectrum of the meso-tetraphenylporphyrin and its Ni derivative (Figure 2c) indicates the resonance signals of Ni-porphyrin complex are found to have shifted upfield as compared to free porphyrin. The presence of a singlet at $8.74 \mathrm{ppm}$ corresponds to the hydrogen atoms of the pyrrole ring. This signal is located at a very low field because of the delocalization of electron of pyrrole ring and the meso-aryl ortho protons resonate as doublet at $8.00 \mathrm{ppm}$ and $7.76 \mathrm{ppm}$ for meta and para, respectively. The Ni (II) porphyrin display upfield chemical shift with respect to their unmetallated porphyrin counterpart. This trend is particularly evident for pyrrole proton resonances on the porphyrin ring that are located closest to the metal center. The protons in the nickel porphyrin are shifted upfield as a result of shielding due to presence of metal to ligand $\pi$ back bonding.

Further, the zinc (II) complexe of $\mathrm{H}_{2} \mathrm{TPP}$ (Figure 2d) indicates that the $\beta$-pyrrole protons resonate as a singlet at $8.96 \mathrm{ppm}$ and the meso-aryl ortho protons resonate as doublet at $8.39 \mathrm{ppm}$ and $7.92 \mathrm{ppm}$ for meso-aryl meta and para protons, respectively, which are slightly downfield (deshielded) compared to free porphyrin where the $\beta$-pyrrole protons resonate as a singlet at $8.87 \mathrm{ppm}$ and the meso-aryl ortho protons resonate as doublet at $8.23 \mathrm{ppm}$ and $7.76 \mathrm{ppm}$ for meta and para, respectively.

In general zinc and bismuth porphyrin protons exhibit downfield ${ }^{1} \mathrm{H}$ NMR chemical shifts, and Ni(II) porphyrin protons display upfield chemical shifts with respect to their unmetallated porphyrin counterparts. This trend is particularly evident for the pyrrole proton resonances on the porphyrin ring that are located closet to the metal center. The protons in the zinc and bismuth porphyrins are shifted downfield due to deshielding caused by the presence of the metal. The protons in the nickel porphyrins are shifted upfield as a result of shielding due to the presence of metal to ligand $\pi$-backbonding. In addition, the porphyrins can be classified as diamagnetic and paramagnetic metalloporphyrins. In diamagnetic metalloporphyrins such as NiTPP and ZnTPP has been observed that $\beta$-pyrrole protons show the maximum low field signal whereas ortho-phenyl protons show comparatively shifting of the signal towards high field and meta and para- phenyl protons are having overlapping resonance signal at still more higher field. When the proton NMR spectra of paramagnetic porphyrins like BiTPP is considered, it is seen that all types of proton signals are shifted to the maximum low field values with broadening of the resonance signals.

\subsubsection{IR Study}

These porphyrins were further characterized by FTIR spectroscopy. Infrared spectra are found to be more useful physical method for investigation and identifying functional groups. The characteristic IR absorption frequencies in the spectral range of $4000-400 \mathrm{~cm}^{-1}$ were measured for free porphyrin and its metal complex. As shown in Table 3, the IR absorption frequencies were different for free base porphyrins and porphyrin complexes with different functional groups. It was found that the $\mathrm{N}-\mathrm{H}$ bond stretching and bending frequencies of free base porphyrins located at $\sim 3314 \mathrm{~cm}^{-1}, \delta \mathrm{N}-\mathrm{H}$ (in 
planarity) and $\delta \mathrm{N}-\mathrm{H}$ (out of planarity) absorption band of porphyrin band is about $964 \mathrm{~cm}^{-1}$ and $798 \mathrm{~cm}^{-1}$. These bands disappear in the all synthesized metalloporphyrins after the metal insertion reactions due to N-H disappear on account of replacement of two acidic hydrogens by the metal ion. This also gives information about the presence or absence of TPP as an impurity in the corresponding metalloporphyrins (MTPP) (Figure 3) and strong band near $1000 \mathrm{~cm}^{-1}$ corresponds to skeletal ring vibration of metal porphyrin agree with the result of literature [9]. The bands at 2,923 2921 $\mathrm{cm}^{-1}$ were assigned to the C-H bond of the phenyl ring and pyrrole ring. The bands at $1559-1598 \mathrm{~cm}^{-1}$ and $1339-1490 \mathrm{~cm}^{-1}$ were assigned to the $\mathrm{C}=\mathrm{C}$ stretching mode and the $\mathrm{C}=\mathrm{N}$ stretching vibration respectively. The bands at $\sim 793-798 \mathrm{~cm}^{-1}$ and $\sim 695-752 \mathrm{~cm}^{-1}$ were respectively assigned to the $\mathrm{C}-\mathrm{H}$ bond bending vibration of para-substituted and ortho-substituted phenyl ring.

\subsubsection{UV-vis Study}

The absorption spectra of porphyrin and its metal complexes were recorded in dichloromethane within the spectral range of $370-700 \mathrm{~cm}^{-1}$. The absorption spectra of free porphyrin (Figure 4) revealed one major intense Soret band and four Q-bands in dichloromethane solution in the ultraviolet part of the spectrum in agreement with the literature [10]. UV-VIS spectroscopy for the free porphyrin showed the characteristic soret band at $418 \mathrm{~nm}$ and Q band at 516, 551, 589 and $645 \mathrm{~nm}$ in dichloromethane (Table 4). The absorption spectrum of porphyrin metal complex (Figure 4) was depicted on the basis of disappearance of I, II, and III bands. This indicates incorporation of metal ion in the porphyrin ring. The electronic absorptions for both metallated and non-metallated porphyrin have been attributed to porphyrin ring based $\pi-\pi^{*}$ electronic transitions.

Table 3. IR/FIR Data Of Free Base Porphyrins And Iron Porphyrin Compounds

\begin{tabular}{|c|c|c|c|c|}
\hline \multirow{2}{*}{ Functional Group } & \multicolumn{4}{|c|}{ Wavenumber $\left(\mathrm{cm}^{-1}\right)$} \\
\cline { 2 - 5 } & H2PPT & ZnPPT & NiPPT & BiPPT \\
\hline$v[\mathrm{NH}]$ & 3314 & - & 2922 & 2921 \\
\hline$v[=\mathrm{C}-\mathrm{H}]$ & 2923 & 2923 & 1384 & 1384 \\
\hline$v[\mathrm{C}=\mathrm{N}]$ & 1490 & 1339 & 1598 & 1559 \\
\hline$v[\mathrm{C}=\mathrm{C}]$ & 1593 & 1596 & 793,695 & 795,721 \\
\hline$\delta[\mathrm{C}-\mathrm{H}]$ & 798,698 & 797,752 & - & - \\
\hline$\delta[\mathrm{NH}]$ & 964 & - & & \\
\hline
\end{tabular}

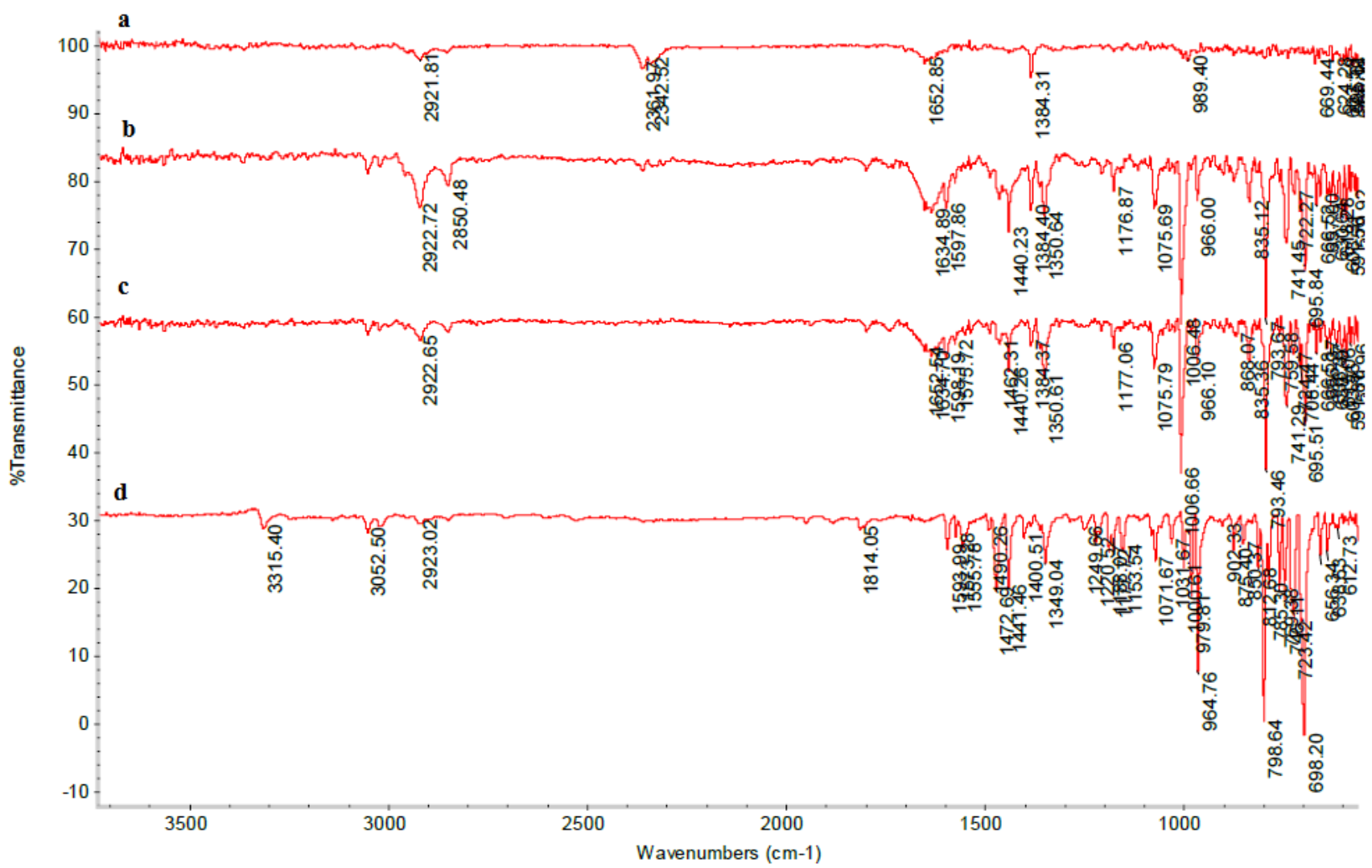

Figure 3. IR spectra of (a) bismuth (III) complexe of $\mathrm{H}_{2} \mathrm{TPP}$ (3a); (b) Nickel (II) complexe of $\mathrm{H}_{2} \mathrm{TPP}$ (3b); (c) zinc (II) complexe of $\mathrm{H}_{2} \mathrm{TPP}$ (3c); (d) free $\mathrm{H}_{2} \mathrm{TPP}$ 

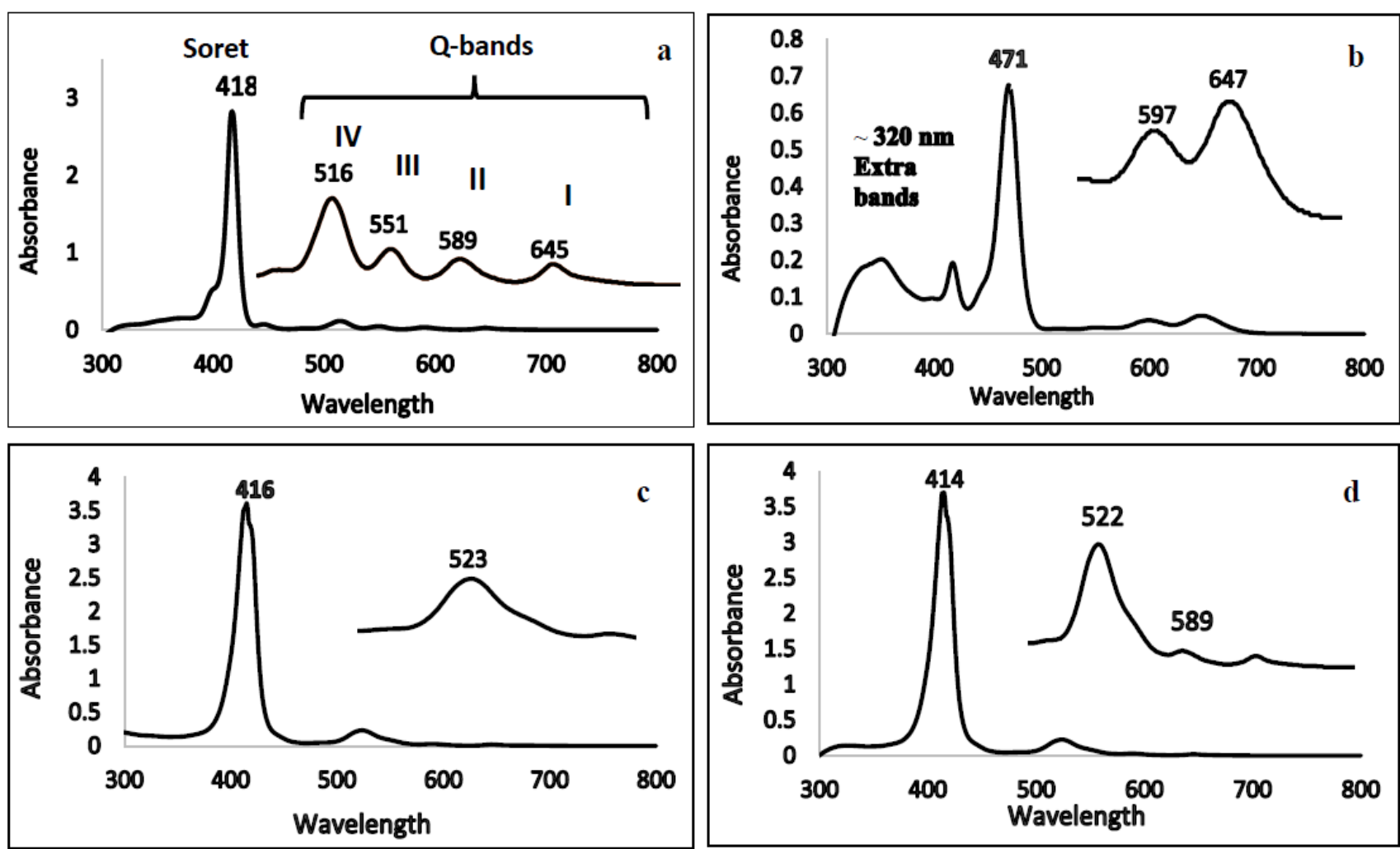

Figure 4. Absorption spectra of: (a) free $\mathrm{H}_{2} \mathrm{TPP}$; (b) bismuth (III) complexe of $\mathrm{H}_{2} \mathrm{TPP}$; (c) Nickel (II) complexe of $\mathrm{H}_{2} \mathrm{TPP}$, (d) zinc (II) complexe of $\mathrm{H}_{2} \mathrm{TPP}$ in $\mathrm{CH}_{2} \mathrm{Cl}_{2}$ in $1 \times 10^{-6} \mathrm{M}$ with in insert the enlargement of $\mathrm{Q}$ region between $480-720 \mathrm{~nm}$

Table 4. UV-Vis Data Of Free Base Porphyrins And Metallated Porphyrins

\begin{tabular}{|c|c|c|c|}
\hline \multirow{2}{*}{ No. } & \multirow{2}{*}{ Compounds } & \multicolumn{2}{|c|}{$\lambda \max (\mathrm{nm})$} \\
\cline { 3 - 4 } & & Soret bands & Q bands \\
\hline 1 & H2PPT & 418 & $516,551,589$ and 645 \\
\hline 2 & ZnPPT & 414 & 522,589 \\
\hline 3 & NiPPT & 416 & 531 \\
\hline 4 & BiPPT & 471 & 600,652 \\
\hline
\end{tabular}

The Bi(III) porphyrins displayed spectra of the hyper p-type [11], which is characteristic of porphyrin derivatives of main group element of lower oxidation state: besides the Soret band around $471 \mathrm{~nm}$ and the two less intense Q bands at 600 and $652 \mathrm{~nm}$, extra absorption bands arose at $\lambda \sim 320 \mathrm{~nm}$ (Figure 4). For Ni (II) porphyrins, as a result of extensive metal $\left(\mathrm{d}_{\mathrm{xz}}, \mathrm{d}_{\mathrm{yz}}\right)$ to ligand $\pi^{*}$ back bonding an increased energy splitting, for porphyrin based $\pi$ - $\pi^{*}$ electronic transition occurs. The increased energy splitting results in hypsochromic shift. Further, coordination with extra ligand causes a general shift of absorption band to higher wavelength. Meso-tetraphenylporphyrin shows the presence of a Soret band at $418 \mathrm{~nm}$. The nickel (II) porphyrin complex produces soret bands at $416 \mathrm{~nm}$, respectively, demonstrating that the trend for increasing red shifts in metalloporphyrins. Absorption of energy manifested in the Soret band is attributable to a single transition affecting the resonating system of the porphyrin ring. Regular metalloporphyrins such as $\mathrm{Zn}(\mathrm{II})$, contain closed-shell metal ions $\left(\mathrm{d}^{0}\right.$ or $\left.\mathrm{d}^{10}\right)$ in which the $\mathrm{d} \pi\left(\mathrm{d}_{\mathrm{xz}}, \mathrm{d}_{\mathrm{yz}}\right)$ metal-based orbitals are relatively low in energy. These have very little effect on the porphyrin $\pi$ to $\pi^{*}$ energy gap in porphyrin electronic spectra.

\section{Conclusions}

In summary, several substituted 5,10,15,20-tetraarylporphyrins were prepared by a straight-forward microwave-assisted experimental protocol, clearly demonstrating its synthetic potential when compared to other conventional synthetic methodologies used for the same purpose. Furthermore, under microwave heating, the synthesis of different 5,10, 15,20-tetraphenylmetalloporphyrins was rapidly and successfully achieved with reasonable yield, starting from the free base and the appropriate metal salts. The usefulness and convenience of the synthetic methods reported here arise from the use of a microwave oven, significant minimization of the reaction times, the amounts of solvents employed and the undemanding workups involved. The data obtained from the spectroscopic analysis confirm the formation of the metalloporphyrins.

\section{Acknowledgements}

The authors are grateful to the Merc Company for the providing with chemicals assistance.

\section{Statement of Competing Interests}

The authors have no competing interests. 


\section{References}

[1] Ferrio, M.A., Relational typologies in couples suffering from psychogenic infertility. Ann Ist Super Sanita, 1992. 28(2): p. 291-3.

[2] Xiang, Z. and K.P. Ravindra, Porphyrin-Carbohydrate Conjugates: Impact of Carbohydrate Moieties in Photodynamic Therapy (PDT). Anti-Cancer Agents in Medicinal Chemistry, 2008. 8(3): p. 241-268.

[3] Mink, D.F.M.a.L.M., J. Chem. Ed., 1996. 73: p. 1180.

[4] Falk, J.E., Porphyrins and Metalloporphyrins. Elsevier, New York, 1975.

[5] Loupy A, P.A., Hamelin J, Texier-Boullet F, Jacquault P and
Mathé D., Synth. Rev., 1998: p. 1213-1234.

[6] Alexandre F-R, D.L., Frère S, Testard A and Thiéry V., Mol. Diversity 2003. 7: p. 237-280.

[7] Polshettiwar, V.V., R. S., Acc. Chem. Res., 2008. 41: p. 629.

[8] Rocha Gonsalves, A.M.d.A.V., J. M. T. B.; Pereira, M. M., J. Heterocyclic Chem., 1991. 28: p. 286.

[9] Liu S Q, S.H.R., Sun Z T, Xu Ji Q and Li D M, Synth. Commun., 2000. 30: p. 2009.

[10] Zhi-Cheng Sun, Y.-B.S., Yang Zhou, Xu-Feng Song and Kai Li Synthesis, Characterization and Spectral Properties of Substituted Tetraphenylporphyrin Iron Chloride Complexes Molecules 2011. 16: p. 2960-2970.

[11] Vogler., K.G., Inorg Chem, 1994. 33: p. 314-318.

(C) The Author(s) 2019. This article is an open access article distributed under the terms and conditions of the Creative Commons Attribution (CC BY) license (http://creativecommons.org/licenses/by/4.0/). 